\title{
Using the Hyatt Regency Skywalk Collapse Case Study in Engineering Education.
}

John W. Lawson

\& Pamalee A. Brady

\begin{abstract}
To this day, the 1981 skywalk collapse in the Kansas City Hyatt Regency resulted in the worst loss of life from a structural engineering mistake in United States history. While many important engineering lessons can be drawn from this disaster, it is just as important to recognize the broader lessons learned in the design and construction process as a whole that can be successfully brought into the classroom. Numerous organizations have undertaken the task of envisioning how engineering education can meet the demands of the future. ABET's baccalaureate degree accreditation criteria, ASCE's Body of Knowledge and Body of Knowledge 2 as well as the National Academy of Engineering have documented the need to change engineering education from its historical focus on technical content knowledge to include greater emphasis on professional issues and to integrate engineering practice into education. To this end teaching methods such as project based learning, active learning and the use of case studies are being explored to address these broader learning outcomes while actively engaging students. Because of the attraction students have in extraordinary events, the Hyatt disaster provides an ideal backdrop to introduce many of the professional issues needed to broaden the undergraduates' learning experience. This paper discusses the use of the Hyatt Regency skywalk collapse in design coursework with specific application to third and fourth year civil and architectural engineering student learning. Besides the traditional concepts of load flow analysis and member design, broader concepts relating to professional roles and responsibilities, design team interplay, the design process, the construction process and professional practice ethics are emphasized.
\end{abstract}

\section{INTRODUCTION}

Today's engineering graduates face a world more complex than ever before. Their engineering profession is being challenged by both technical complexities and societal complexities. Historically, engineering education has primarily focused on technical content to provide a strong theoretical foundation for future practicing engineers. Learning to apply their technical knowledge as well as experiencing the professional and societal issues was relegated to their early years of employment under the guidance of a mentor or watchful supervisor. 
In a similar fashion, other professionals in the construction industry had apprentice and journeymen approaches to teach the broader professional issues on the job. However, in today's fast-paced society, with increasing job complexity and competing priorities for limited time, there has been less fostering within the engineering profession and more relying upon skills acquired during college education. The expectation has become that engineering graduates must be well prepared to meet the new challenges of not only heightened technical complexity but also escalating professional complexity.

As engineering students begin their career path, they are facing challenges of competing and conflicting demands. Exciting and dramatic projects must be economically feasible; durable materials must be sustainable, and more daring structures must be at the same time safer. Under this backdrop, the engineering office is often expected to meet unrealistic deadlines, for lower fees, while maintaining a high level of quality control to ensure human safety, health, and welfare. These professional and technical challenges require engineering students to be adept in interdisciplinary and teamwork skills, have refined communication skills, appreciate responsibility and accountability, and embark on lifelong learning. It has been well established that the education of the future engineer must incorporate these professional issues in the classroom as well as into the early years of employment to face these challenges (ASCE Body of Knowledge Committee, 2008).

The Kansas City Hyatt Regency skywalk collapse has at its heart non-technical issues of communication, interdisciplinary teamwork, and ethical challenges; and provides an excellent tool as a case study to engage students while teaching these boarder professional issues. This paper is not meant to educate the reader of the events that led up to and followed the disaster; but instead demonstrate the usefulness of this using this tragedy as a platform to engage engineering students and introduce broad professional issues into the classroom.

\section{LEARNING OBJECTIVES}

It is now widely accepted that the incorporation of both technical and professional issues is necessary in an undergraduate engineering education. The National Academy of Engineering (2005) and ABET's accreditation criteria (ABET, 2010) emphasize this objective, yet the need for integrating professional issues into the classroom is clearest in the ASCE's report Civil Engineering Body of Knowledge for the 21st Century: Preparing the Civil Engineer for the Future (ASCE Body of Knowledge Committee, 2008).

The objective of ASCE's Body of Knowledge report is to provide a guide to reform education and pre-licensure experience to shape the civil engineer of the future. The vision of the civil engineer in year 2025 is seen as being quite different from the past due to society's dramatic globalization with the complexities of sustainability demands, risk management, and the larger number of interested parties in a particular project. ASCE's Body of Knowledge report identifies the knowledge, skills and 
attitudes necessary to enter the practice of civil engineering at the professional level, through education and early experience. It is ASCE's hope that engineering curricula and pre-licensing experience will change over time towards this model. And indeed, ABET education accreditation and National Council of Examiners for Engineering and Surveying (NCEES) engineering licensing criteria are working together with ASCE's Body of Knowledge for an integrated process towards licensing.

ASCE's Body of Knowledge guidelines contain the traditional instructional objectives in foundational and technical outcomes. These basics broadly include work in math and sciences, experimentation and problem solving. What have been more difficult to incorporate in existing curricula are the nine professional issue outcomes identified. Figure 1 lists the desired professional outcomes and their respective level of achievement to be reached upon completing an undergraduate education in civil engineering (on a scale of 6). In the ASCE's outcomes rubric it is interesting to note that none of the professional outcomes are assigned to the master's degree education process. The master's degree is recommended to focus exclusively on technical experimentation, problem solving and area specialization.

\begin{tabular}{|c|c|}
\hline Level & Professional Outcome \\
\hline 4 & Communication \\
\hline 2 & Public Policy \\
\hline 2 & Business and Public Administration \\
\hline 3 & Globalization \\
\hline 3 & Leadership \\
\hline 3 & Teamwork \\
\hline 2 & Attitudes \\
\hline 3 & Lifelong Learning \\
\hline 4 & Professional and Ethical Responsibility \\
\hline
\end{tabular}

\section{Figure 1. ASCE's Body of Knowledge Professional Issue Outcomes at the Undergraduate Level}

The level of outcome achievement is tied to the cognitive domain of Bloom's Taxonomy. The two highest professional issues on this cognitive achievement scale are Communication and Professional and Ethical Responsibility. While some educators may simply regard communications as being satisfied by their institution's general breadth requirements in speech or writing, the intent is far more extensive. Undergraduates are expected to understand communication issues within the professional practice, including graphic presentation, construction drawings, computer models, hand sketches, verbal instructions, technical and non-technical writing. Reinforcement of these professional issue outcomes are also addressed in ABET's $a$ - $k$ criteria for baccalaureate engineering degree programs. Criteria $f, g$ and $h$ specifically address: an understanding of professional and ethical responsibility, an ability to communicate effectively and the broad education necessary to understand the impact of engineering solutions in a global and societal context, respectively. 


\section{PROFESSIONAL ISSUES IN THE HYATT REGENCY COLLAPSE}

The Kansas City Hyatt Regency skywalk collapse is a uniquely suited case study to engage and educate students in the more important professional outcomes desired by the Body of Knowledge. The two most significant professional issues identified by ASCE's Body of Knowledge are communications and professional ethics and responsibilities, both of which are spotlighted in the collapse.

The major issue at the heart of the Hyatt Regency disaster is the breakdown of communications (Banset, 1989). There was a failure for the structural engineer to clearly communicate his intent to the steel fabricator his role or responsibility in the design of the critical rod-to-beam connection. In addition, the failure of this connection was traced back to an inadequate design that was not properly communicated graphically in the construction documents or verbally in subsequent phone calls between the two disciplines.

The ambiguous communication between the structural engineer and the steel fabricator was identified in Missouri's Administrative Hearing as a major factor in the disaster (Deutsch, 1985). The Commission report states that the structural engineer "bears the burden of communicating his intent to the contractor and assumes the risk of confusion or noncommunication.” The report also states, “...the burden and responsibility for clear communication lies with the engineer who assumes the risk of ambiguity in his design drawings."

In line with another learning outcome is the understanding of professional responsibility and its ethical implementation by the Hyatt's structural engineer. Despite making assurances to the owner and architect of doing so, the structural engineer never ran calculations on the flawed connection. In addition, the structural engineer and the steel fabricator did not properly coordinate their responsibilities in the connection design; and in their rush to complete the job, the critical shop drawings never got a proper review despite the engineer's review stamp. Valuable opportunities exist in such a teachable case study to highlight important professional issues in communications, professional responsibilities, professional ethics, and interdisciplinary teamwork.

\section{TEACHING TECHNIQUES}

Case studies lend themselves as a powerful tool for contextual learning of professional issues. These are real-life stories with characters, a setting, a plot with a struggle, and an outcome; and when presented in story form, students are immersed briefly into a chain of unfolding events with an underlying professional context. Weaving factual information into an emotional story has been shown to develop better comprehension and long-term memorization [Abrahamson, 1998; Haven, 2007]. In addition, a deeper emotional connection is made allowing the students to personally experience and internalize engineering judgment dilemmas and ethical decisions. This is very difficult to achieve in the classroom through any other method of instruction. 
When case study events are presented in chronological order with a surprise ending, teaching tends to take an inductive approach rather than a traditional deductive style. Instead of first describing how mistakes were made along the way in the Hyatt disaster, an inductive approach reveals the disaster and then encourages the students to determine the cause by sifting through the facts. In general, the inductive approach first gives students the reason why they need to learn the material and then challenges them to make logical sense of a complex problem. This problem-solving skill is imperative to the success of life-long learning. The inductive approach to student learning is supported by the best research on learning currently available (Prince, 2006).

Another powerful teaching technique well-suited for the Hyatt Regency case study is the use of project-based active learning strategies. This is a dynamic approach to teaching with a high level of student engagement and participation. Research indicates that students are more likely to retain the knowledge gained through this approach than through traditional lecture-centered or textbook-centered learning. In addition, students develop confidence and self-direction as they move through both teambased and independent work. There are various approaches to implementing active learning strategies in conjunction with inductive learning and storytelling, and a few approaches considered by the authors will now be discussed.

\section{HYATT REGENCY COLLAPSE CASE STUDY APPROACHES}

Various approaches are available to introduce case studies to students. One author's approach to introducing the Hyatt Regency case study lesson involves only one or two days of class time. The students are first introduced to a "hypothetical" hotel project as an in-class exercise where the instructor challenges them to develop engineering ideas to span elevated walkways across a $120-\mathrm{ft}$ wide atrium space. Students break into small groups and develop schematic design solutions for two stacked, visually floating, walkways across the atrium space. During the exercise, the instructor plays the role of the architect guiding and challenging students to make the walkways thin and visually floating. This is an excellent time to provide an overview of the entire design process from the developer's original concept to the completed construction drawings as the students experience a portion of this process. Additionally, the professional roles and responsibilities of the developer, architect and structural engineer are discussed in this context.

At the conclusion of the groups' schematic design exercise, the instructor compares and contrasts the different approaches developed. While some design solution differences may simply be a matter of different perspectives, other differences could be attributed to intentionally ambiguous communications from the instructor. An important lesson in clear communications and the pitfalls of inappropriate assumptions can be taught here, foreshadowing later parts of the case study.

It is at this point that the instructor explains that this exercise is actually based on a real design problem, and then unveils the as-designed solution with three pairs of continuous suspended rods supporting both stacked walkways. Once it is revealed that this is a real project, the instructor can engage the students further using the 
actual setting and participants' names to begin to tell the story. The as-designed solution is discussed in general and contrasted with the student designs, and it is of some benefit to encourage the students to mentally adopt the as-design solution as reasonably appropriate.

Using the power of storytelling the instructor can slowly unveil the story with plot twists and emotional surprises providing drama, but importantly allowing the instructor to control the student's experience and to introduce key points in communication failures, ethical dilemmas, professional roles and responsibilities. The revelation that the adopted design detail led to 114 deaths provides an emotional attachment as the students search for causes. The process provides students with a self-motivated inductive learning approach.

Similar to an actual investigation, the instructor slowly reveals more information being learned of the collapse. Using an important active learning approach, students are periodically polled with a show of hands or electronic clickers to observe opinion shift as to perceived fault. Using the following hypothetical series of discoveries, the instructor gradually introduces many professional issues while students critically think of responsibilities and ethical challenges:

Investigation discovery \#1: The hanger rods pulled through the inadequately designed box beam flanges.

Teachable moment: Basic technical design concepts may be introduced. Graphic communication methods of drawings and details are introduced.

Students' general opinion: The structural engineer is at fault.

Investigation discovery \#2: The steel fabricator revised the single continuous rod design to a design using two separate rods, thus doubling the load on the failed box beam connection.

Teachable moment: The roles and responsibilities of the engineer and fabricator are compared and contrasted.

Students' general opinion: Fault has shifted towards the steel fabricator.

Investigation discovery \#3: The steel fabricator explains that the single rod design is impractical to build, as it requires a fully threaded rod design and mid-length nut assembly.

Teachable moment: The issue of constructability is introduced and whose responsibility it is.

Students' general opinion: Class split between the engineer and fabricator as to fault.

Investigation discovery \#4: The steel fabricator's shop drawings indicate the revised connection was communicated to the engineer who reviewed it and stamped his approval.

Teachable moment: Introduction of the purpose of steel shop drawings, with roles and responsibilities of the involved disciplines. 
Students' general opinion: Fault has shifted back to the structural engineer.

Investigation discovery \#5: The engineer says he doesn’t "approve” shop drawings but only provides a cursory review as indicated on the stamp.

Teachable moment: Ambiguous communications of responsibility and expectations are a major factor in this disaster. Additionally, the introduction of fast-track projects and this delivery mode's rushed nature are discussed.

Students' general opinion: Class becomes split as to fault assignment.

Investigation discovery \#6: The steel fabricator's detailer and the architect testify that they had undocumented phone calls with the engineer regarding the connection revision, and that they were assured by the engineer that it was safe. Engineer admits to some of the phone calls, but denies assuming responsibility for the connection.

Teachable moment: Communications need to be clear and documented to avoid ambiguity and accountability.

Students' general opinion: Fault shifts more towards the engineer again.

Investigation discovery \#7: During construction, a 2700 square foot portion of the atrium collapsed due to a poor connection, alarming the owner. The engineer assured the owner that every atrium detail would be checked for safety. Despite being compensated for checking the atrium again and writing a letter to the architect assuring safety of the suspended walkways, a review commission determined that engineering calculations of the box-beam and connection were never made.

Teachable moment: Ethical behavior serves an important purpose.

Students' general opinion: The engineer is at fault.

Additional hypothetical scenarios for discussion:

What if the steel fabricator dumped over 500 pages of shop drawings on the engineer for immediate review?

What if it was standard practice for the steel fabricator to complete the design of typical connections?

What if the engineer strongly suggested to the architect it would be safer to support the walkways with columns instead of suspended rods?

As this case study is presented with unfolding drama, students are immersed into different situations that challenge their perceptions and attitudes. This experiential approach can instill professional ethics very successfully, and gives the students the practice of making difficult judgments before beginning their careers. With both intellectual and emotional engagement, students are in a valuable learning environment to introduce ASCE's and NSPE's Code of Ethics and to introduce other 
professional learning outcomes in communications, interdisciplinary teamwork, roles and responsibilities, and leadership.

Student response to the introduction of case studies has been overwhelmingly positive. During the exercises and discussions, student engagement is very apparent with insightful questions and full attention throughout the classroom.

Another instructor takes a different approach using the Hyatt walkway collapse within a professional issues module that is a part of a broad quarter-long design problem. The objectives of the module are to discuss an engineer's professional responsibilities and the relationship of these responsibilities to society; to discuss various engineering ethics codes; to identify the need for an ethics code; to emphasize the importance of communication - both written and verbal; and, within a setting - the Hyatt walkway collapse - identify ethical concerns, describe what action should be taken and discuss the ethical basis for these actions. The case works well within the context of a design project wherein the students are progressing from conceptual design through final design and developing a calculation package and set of construction documents. The lessons require limited class time but make use of asynchronous discussions conducted through a website.

The instructor begins the module by conducting an assessment of the students' understanding of what distinguishes engineering as a profession, what is an engineer's responsibility and to whom is an engineer responsible; and what if any is the distinction between professional ethics and personal ethics? The instructor then begins a discussion of the assessment topics along with an introduction to the steps to licensure as a professional engineer and structural engineer, the latter of which always elicits much student inquiry. The responsibility of engineers to the society as well as the public trust placed in the profession to establish standards of conduct and to enforce those standards highlights the importance of professional ethical tenets beyond personal opinions. The ASCE and NSPE codes of ethics are introduced along with some history of their development. A brief PowerPoint presentation is used to open the story of the Hyatt Regency design and construction - a project much larger but similar to the one they are undertaking. The context of practice in the 1980s is presented; the roles of individuals are described. The story is set in motion. The walkway collapse is not yet discussed.

The students are then divided into four teams; each team is assigned four technical papers (Gillum, 2000; Luth, 2000; Moncarz, 2000; Pfatteicher, 2000) for reading and discussion within their teams. Each team is given a list of questions for discussion on the technical / human / organizational / socio-cultural aspects of the case. Sample questions from each of these four areas follow:

Technical: Describe the features of the critical detail that failed in the walkway collapse.

Human factors: As an entry level engineer what steps will you take when new situations arise in a design project that you have not faced before? How 
will you convey your knowledge and understanding and what you don't yet understand?

Organizational: What is the responsibility of the Engineer of record?

Socio-cultural: What do you believe should be the responsibility of building departments for projects such as the Hyatt Regency Hotel? How can building departments provide the level of review appropriate for such a project?

The students are also required to submit a question that they think should be answered regarding each aspect of the case.

Over a period of approximately two weeks the students answer the questions and undertake an asynchronous discussion with one another in the four areas via an electronic discussion board. During this period they are engaged in the structural detailing of a multi-story building in the classroom. The final task of the assignment is to compile a summary presentation of the team's perspective of what can be learned from these events. A post assessment on professional ethics follows sometime later in the term.

Student responses in the asynchronous discussion for each aspect of the case are evaluated based on their depth of inquiry and reflection of the reading. A team score is assigned. Some responses provided by students to posed questions include:

"[in new modes of delivery and contractual arrangements] early delineation of responsibilities should stimulate cooperation and communication."

"One thing that [is mentioned] that I have not considered is being open to everyone and letting them know that you are not completely familiar with the problem, this can help with avoiding any mishaps and it also reaffirms the team aspect of a project."

"...this situation shows that more structured communication between parties was necessary to avoid problems."

Suggested questions by students include:

"How can the lack of communication and ineffective collaboration between the design and construction professionals that characterized this project be prevented in the future?"

“...about having an onsite engineer...what should an onsite engineer be looking for and checking during construction?"

The concluding student PowerPoint presentation and final professional engineering ethics quiz administered following the case study module indicate that students develop a keen awareness of the responsibilities embodied in engineering practice. Future assessments will include a student survey evaluating the contribution of case 
studies to both technical and ethics learning. The survey was developed by faculty at Cleveland State University for evaluating individual course learning with respect to ABET's $a-k$ criteria as well as the impact of case studies, along with other course elements, in contributing to student interest in the course material.

\section{OTHER APPROACHES}

The two presented approaches are those most familiar to the authors. A myriad of other approaches are possible to achieve the similar learning objectives. The use of active learning strategies enhances student engagement and material retention, and should be strongly considered. Another such approach with strong potential is to have each student assume the role of a Kansas City Star newspaper reporter and write an article with the intended audience being the general public. This exercise challenges students to research complex events and then disseminate them into basic concepts and translate technical terminology into lay terms. Student then exchange the proposed articles with each other and then take on the role of newspaper editor for a peer review. To enhance the active learning and engagement, the articles are formatted similar to newspaper with multiple column formatting, headline, photograph, several figures, and notable quotes. With a restrictive word count it will be impossible for students to have a comprehensive discussion; thus students are challenged to prioritize the relevant information from the public's perspective, and to be as succinct as possible.

A similar role playing approach places the students into the uncomfortable position of representing Hyatt Hotels. In this exercise, students assume the role of Hyatt's public relations officer who must write a letter to the disaster survivors explaining what was determined to be the cause of the collapse. This style of letter will be quite different than a newspaper article in its demeanor. The use of analogies is strongly encouraged to help relate the mechanics of the collapse with everyday concepts the intended audience is familiar with. Another important aspect of this exercise is students' selection of language and disposition when communicating with survivors who are still healing physically and mentally from their experience. Students are challenged to be transparent and open, yet to experience the underlying fear of a disgraced corporate image and potential liability. These are real professional conflicts that occur in an engineering office, and the ethical implications of different courses of action can be discussed.

Another approach which has been shown to be very successful is the implementation of a mock trial or public inquiry (Jennings, 2000). Students form teams to research the disaster, form opinions, and then support or even argue their findings to the rest of the class. This student-based learning approach encourages students to be inquisitive about the roles, responsibilities, and priorities of the engineering profession. In addition, student-based learning as opposed to teacher-imparted learning fosters student self-discovery, an important trait for lifelong learning. These outcomes are core professional issues desired by ASCE's Body of Knowledge and ABET. An additional benefit of this approach is that student-based learning has less 
reliance on the instructor's practical experience, thus making this case study approach more acceptable to the entire faculty. Detailed descriptions of the events from various perspectives are widely available for students to draw upon, especially five articles published in the Journal of Performance of Constructed Facilities (Gillum, 2000; Luth, 2000; Moncarz, 2000; Pfatteicher, 2000; Rubin, 1987).

Using approaches that involve teamwork, communications within a group, communications to lay people, and self-directed discovery creates an experiential learning environment that is similar to the engineer's practice environment. These approaches not only allow students to experience some of the professional issues in a design office, but also allow students to possibly connect with how these professional issues affected the initiation of the Hyatt Regency disaster.

\section{CONCLUSION}

Traditional classroom assignments involve a hypothetical situation with a single solution or obvious best answer. The engineering profession is far more complex with competing priorities, numerous uncertainties, and several feasible solutions, all subjected to various human factors such as communication, risk adversity, and our ability to work with others constructively. The vision of the future engineer has embraced the need to educate towards these professional issues for the benefit of the profession and society.

Using case studies, active learning techniques, and student-based approaches are powerful tools educators use to engage students and introduce professional issues. The Hyatt Regency skywalk collapse is well suited to assist educators towards the outcomes desired for the future engineer. Whether the instructor has practitioner experience or is more comfortable in academia, different approaches are available to match the instructor's level of involvement and past experiences.

It is especially rewarding as instructors to witness increased levels of student engagement and excitement while students learn an important chapter of our profession's past and interlacing the more mundane professional issues into the subject matter. Others are encouraged to find other significant events and engaging teaching approaches to reach the same outcomes.

\section{REFERENCES}

ABET (2010). Criteria for Accrediting Engineering Programs, Engineering Accreditation Commission, ABET, Inc., 111 Market Place, Suite 1050, Baltimore, MD 21202, http://www.abet.org/.

Abrahamson, C. (1998). "Storytelling as a Pedagogical Tool in Higher Education," Education,_Vol. 118. 
ASCE Body of Knowledge Committee. (2008). Civil Engineering Body of Knowledge for the 21st Century: Preparing the Civil Engineer for the Future, $2^{\text {nd }}$ Edition, Reston, VA; http://www.asce.org/raisethebar.

Banset, E. and Parsons, G. (1989). "Communications Failure in Hyatt Regency Disaster," Journal of Professional Issues in Engineering, Vol. 115, No. 3. ASCE, Reston, VA.

Deutsch, J. (1985). "Report of the Administrative Hearing Commission, State of Missouri." Case No. AR-84-0239, Missouri Board of Architects, Professional Engineers, and Land Surveyors vs. Daniel M. Duncan, Jack D. Gillum, and G.C.E. Int., Inc., Jefferson City, Mo.

Gillum, J. (2000). "The Engineer of Record and Design Responsibility," Journal of Performance of Constructed Facilities, Vol. 14, No. 2. ASCE, Reston, VA.

Haven, K. (2007). Story Proof: The Science behind the Startling Power of Story, Libraries Unlimited, Westport, CT.

Jennings, A. and Mackinnon, P. (2000). "Case for Undergraduate Study of Disasters," Journal of Performance of Constructed Facilities, Vol. 14, No. 1. ASCE, Reston, VA.

Luth, G. (2000). "Chronology and Context of the Hyatt Regency Collapse,” Journal of Performance of Constructed Facilities, Vol. 14, No. 2. ASCE, Reston, VA.

Moncarz, P. and Taylor, R. (2000). "Engineering Process Failure - Hyatt Walkway Collapse," Journal of Performance of Constructed Facilities, Vol. 14, No. 2. ASCE, Reston, VA.

National Academy of Engineering. (2005). Educating the Engineer of 2020: Adapting Engineering Education to the New Century, National Academies of Sciences, Washington, DC.

Pfatteicher, S. (2000). “'The Hyatt Horror': Failure and Responsibility in American Engineering,” Journal of Performance of Constructed Facilities, Vol. 14, No. 2. ASCE, Reston, VA.

Prince, M. J., and Felder, R. M., 2006. "Inductive Teaching and Learning Methods: Definitions, Comparisons, and Research Bases," Journal of Engineering Education, Vol. 95.

Rubin, R. and Banick, L. (1987). “The Hyatt Regency Decision: One View,” Journal of Performance of Constructed Facilities, Vol. 1, No. 3. ASCE, Reston, VA. 